\title{
SEROPREVALENCIA DE Toxoplasma gondii EN LLAMAS DE DOS FUNDOS GANADEROS DE LA PROVINCIA DE MELGAR, PUNO
}

\author{
Gualberto Marcas C. ${ }^{1}$, Amanda Chávez V. ${ }^{2,3}$, Eva Casas A. ${ }^{2}$, \\ Wilber García C. ${ }^{4}$ y Néstor Falcón P. ${ }^{5}$
}

\section{Abstract}

\begin{abstract}
The aim of this study was to determine the seroprevalence of Toxoplasma gondii in female llamas from two farms located in the Melgar province, Puno. A total of 284 blood samples were tested using the indirect immunofluorescence test (IFAT) to detect antibodies against $T$. gondii. The results showed that $47.5 \pm 5.8 \%(135 / 284)$ of the samples had antibodies and they increased with age. The seroprevalence from birth till 2 years, 2 4 years, $>4-6$ years, and $>6$ years was $33.8 \pm 11.0,51.2 \pm 10.8,56.8 \pm 14.6$, and $50.6 \pm 10.5 \%$, respectively. There were significant differences $(\mathrm{p}<0.05)$ in the frecuency of female reactors between farms. Age and farm variables were considered as risk factors for the infection with Toxoplasma gondii $(\mathrm{p}<0.0001)$.
\end{abstract}

Key words : toxoplasmosis, seroprevalence, IFAT, llama, Puno

\section{Resumen}

El objetivo del estudio fue determinar la seroprevalencia del Toxoplasma gondii en llamas hembras de dos fundos ganaderos de la provincia de Melgar, Puno. Se colectaron sueros sanguíneos de 284 animales para la detección de anticuerpos mediante el método de Inmunofluorescencia Indirecta (IFI). El $47.5 \pm 5.8 \%$ (135/284) del total de las muestras presentaron anticuerpos. La frecuencia de reactores se incrementó en relación directa con la edad de los animales (nacimiento-2 años: $33.8 \pm 11.0 \%$; > 2 a 4 años: $51.2 \pm 10.8 ;>4$ a 6 años: $56.8 \pm 14.6 \%$; y $>6$ años: $50.6 \pm 10.5 \%$ ). Se encontraron diferencias estadísticas $(\mathrm{p}<0.05)$ en la frecuencia de reactores entre fundos. Además, se halló que la variable edad y zona de muestreo representan un factor de riesgo para la infección con $T$. gondii $(\mathrm{p}<0.0001)$.

Palabras clave: toxoplasmosis, seroprevalencia, IFI, llamas, Puno

\footnotetext{
${ }^{1}$ Práctica privada

${ }^{2}$ Laboratorio de Microbiología y Parasitología Veterinaria, FMV-UNMSM

${ }^{3}$ E-mail: a_chavez_g@hotmail.com

${ }^{4}$ Estación Experimental del Centro de Investigación IVITA-Maranganí, FMV-UNMSM

${ }^{5}$ Laboratorio de Medicina Veterinaria Preventiva, FMV-UNMSM
} 


\section{INTRODUCCIÓN}

La toxoplasmosis es una enfermedad producida por el protozoario Toxoplasma gondii. Este parásito fue inicialmente aislado en roedores en los que producía síntomas nerviosos inespecíficos, pero en la actualidad se sabe que puede afectar a una amplia variedad de hospederos, incluyendo ovinos y caprinos, en los que puede producir severos problemas reproductivos. En países ovejeros como Australia y Nueva Zelanda se ha estimado que las pérdidas de corderos debido a toxoplasmosis varían entre 5 y $50 \%$ (Jacobs, 1964).

La toxoplasmosis es habitualmente asintomática en humanos y en la mayoría de los animales. Las formas clínicas son variables dependiendo del órgano o sistema donde se multiplica el parásito. Solamente en la primo infección del humano, ovinos y caprinos gestantes, el parásito cruza la placenta, infectando al feto con consecuencias serias dependiendo del momento de la infección. En pacientes con inmunosupresión, la toxoplasmosis es una infección mucho más seria, causando síntomas severos con una alta mortalidad y morbilidad; de allí que se le considere entre las enfermedades oportunistas que con mayor frecuencia se presenta acompañando a los casos de SIDA, enfermedad de Hodgking y leucemia (Acha y Szyfres, 1992).

En las zonas andinas, la explotación de camélidos sudamericanos es muy importante para las comunidades campesinas porque obtienen recursos como fibra y carne (Calle, 1982). Uno de los principales problemas en la crianza de camélidos sudamericanos es el bajo porcentaje de natalidad (Raggi, 1992). En esas zonas se tienen antecedentes de muerte embrionaria, abortos y mortalidad de crías recién nacidas, similares a los reportados por ovinos afectados con toxoplasmosis.

Debido a la escasa información del rol patológico del $T$. gondii en camélidos sudamericanos, se hace necesario ampliar la investigación en esta área, por lo que el presente trabajo tuvo como objetivo determinar la seroprevalencia de toxoplasmosis en llamas hembras en la provincia de Melgar, Puno, y contribuir a un mejor conocimiento de la epidemiología de la toxoplasmosis en el país.

\section{MaterRales y Métodos}

El estudio fue realizado en llamas hembras de dos fundos ganaderos localizados en la provincia de Melgar, departamento de Puno, y a una altura superior a los 4,000 $\mathrm{msnm}$. Las poblaciones evaluadas corresponden al fundo San Luis del Centro de Investigación IVITA-Maranganí y al fundo del Centro Experimental de Machuwasi de la Universidad Nacional del Altiplano (UNA). El tamaño de muestra fue de 284 animales seleccionados al azar, luego de la estratificación por fundo ganadero según población estimada. El tamaño muestral se determinó mediante la fórmula para poblaciones finitas con $95 \%$ de confianza y $5 \%$ de precisión, con una prevalencia anterior de 30\% (Daniel, 1996; Gómez et al., 2003).

Las muestras de sangre fueron tomadas por punción a la vena yugular y transportadas al Laboratorio de Microbiología del IVITA-Maranganí, para la obtención del suero sanguíneo. Las muestras procesadas fueron colocadas en viales y transportadas al Laboratorio de Parasitología de la Facultad de Medicina Veterinaria de la Universidad Nacional Mayor de San Marcos, donde fueron congeladas a $-20{ }^{\circ} \mathrm{C}$ hasta su procesamiento.

Para la determinación de anticuerpos contra $T$. gondii se utilizó la prueba de Inmunofluorescencia Indirecta (IFI) utilizada por Tress et al. (1993) y modificada en los laboratorios de parasitología de la Universidad Complutense de Madrid y de la Facultad de Medicina Veterinaria de la UNMSM, Lima. Los resultados son expresados en porcentajes teniendo en consideración la positividad de los sueros a la prueba serológica, calculándose los intervalos de confianza respectivos para los dos grupos según 
Cuadro 1. Seroprevalencia de Toxoplasma gondii en llamas hembras en dos fundos ganaderos de la provincia de Melgar, departamento de Puno. 2002

\begin{tabular}{lccc}
\hline \multirow{2}{*}{ Fundo } & \multicolumn{2}{c}{ Animales } & \\
\cline { 2 - 3 } & Muestreados & Positivos & \\
\hline San Luis & 198 & 118 & $59.6 ? 6.8$ \\
Machuwasi & 86 & 17 & $19.8 ? 8.4$ \\
\hline Total & 284 & 135 & $47.5 ? 5.8$ \\
\hline
\end{tabular}

${ }^{1}$ Intervalo de confianza del $95 \%$

Cuadro 2. Seroprevalencia de T. gondii, en llamas hembras según grupo etáreo y zona de muestreo en dos fundos ganaderos de la provincia de Melgar, departamento de Puno. 2002

\begin{tabular}{cccccc}
\hline \multirow{2}{*}{$\begin{array}{c}\text { Edad } \\
\text { (años) }\end{array}$} & \multicolumn{2}{c}{ San Luis } & \multicolumn{2}{c}{ Machuwuasi } & Total \\
\cline { 2 - 6 } & $(\text { Pos/Total })^{1}$ & Prev. $^{2}$ ? IC $^{3}$ & (Pos/Total) & Prev. \pm IC & Prev. \pm IC \\
\hline 0 a 2 & $24 / 60$ & $40.0 \pm 12.4$ & $0 / 11$ & $0.0 \pm 0.0$ & $33.8 \pm 11.0$ \\
?2 a 4 & $39 / 64$ & $60.9 \pm 12.0$ & $3 / 18$ & $16.7 \pm 17.2$ & $51.2 \pm 10.8$ \\
?4 a 6 & $20 / 26$ & $76.9 \pm 16.2$ & $5 / 18$ & $27.8 \pm 20.7$ & $56.8 \pm 14.6$ \\
?6 & $35 / 48$ & $72.9 \pm 12.6$ & $9 / 39$ & $23.1 \pm 13.2$ & $50.6 \pm 10.5$ \\
\hline
\end{tabular}

${ }^{1}$ Positivos/Total de animales

${ }^{2}$ Prevalencia (\%)

${ }^{3}$ Intervalo de confianza del $95 \%$

procedencia y edad de los animales; del mismo modo se realizó la prueba de regresión logística para evaluar el grado de asociación y el riesgo de infección para las variables zona de estudio y edad de los animales.

\section{Resultados y Discusión}

Se halló una seroprevalencia de $47.5 \%$ (135/284) a T. gondii (Cuadro 1); resultado que corrobora la amplia distribución de la infección por toxoplasmosis en diferentes especies de animales de sangre caliente y en camélidos sudamericanos. Además, estos resultados demuestran que los ooquistes del parásito pueden permanecer viables en los
Andes por encima de los 4,000 msnm. Estos resultados no difieren de los de los reportados por Leguía et al. (1988) y Gómez et al. (2003) quienes hallaron prevalencias de $50 \mathrm{y}$ $30 \%$ en alpacas y llamas hembras, respectivamente. Otros estudios realizados en el Perú en ovinos y caprinos por Vidal (1990) y Rojas (1990) mostraron prevalencias de 39 y $58 \%$, respectivamente; cifras que son consideradas moderadamente elevadas en el país.

El carácter cosmopolita de la enfermedad y su amplia distribución ha sido comprobado por la presencia de reactores en diferentes partes del mundo; así, Dubey et al. (1992) halló una prevalencia de 33.5\% en llamas (EEUU), Elamin et al. (1992) reportan $67 \%$ en camellos de Sudán, mientras que 
Cuadro 3. Evaluación de las variables edad y zona de muestreo como factor de riesgo para la infección de Toxoplasma gondii en llamas hembras en dos fundos ganaderos de la provincia de Melgar, Puno. 2002

\begin{tabular}{ccccc}
\hline & Nivel de & & \multicolumn{2}{c}{$\mathrm{IC}^{1}$ del $95 \%$ del Odds Ratio } \\
\cline { 4 - 5 } Variable & Significancia & Odds Ratio & $\begin{array}{c}\text { Limite } \\
\text { inferior }\end{array}$ & $\begin{array}{c}\text { Limite } \\
\text { Superior }\end{array}$ \\
\hline $\begin{array}{l}\text { Zona } \\
\text { San Luis }\end{array}$ & 0.000 & 7.436 & 3.334 & 16.584 \\
Edad & & & & \\
?2 a 4 & 0.007 & 2.522 & 1.286 & 4.944 \\
?4 a 6 & 0.000 & 6.826 & 2.584 & 18.032 \\
?6 & 0.000 & 20.757 & 7.659 & 56.252 \\
\hline
\end{tabular}

${ }^{1}$ Intervalo de confianza del $95 \%$

Zhang et al. (2000) encontraron prevalencias que variaban entre 11 y $69 \%$ en diferentes especies de aves, primates, carnívoros y herbívoros silvestres en un zoológico de China.

El análisis individual por fundo evaluado reporta una prevalencia de $59.6 \%$ (118/ 198) y $19.8 \%(17 / 86)$ para los fundos San Luis y Machuwasi, respectivamente (Cuadro 1). Esta diferencia en los resultados puede explicarse por las características particulares de crianza en los dos fundos evaluados, a pesar de encontrarse a altitudes andinas similares. El Fundo San Luis se encuentra rodeado de centros poblados donde se pudo observar la presencia de felinos domésticos dentro del seno familiar local, mientras que Machuwasi es un centro dedicado exclusivamente a la crianza de camélidos sudamericanos y se encuentra alejado de los centros poblados, restringiéndose el ingreso de otras especies, y de esa forma disminuyendo el riesgo de infección de las praderas andinas.

El manejo de los camélidos sudamericanos juega un rol significativo en la transmisión de la infección a $T$. gondii; así, los animales en épocas de seca son llevados, especialmente las hembras, a las zonas bajas en busca de mejores pastos, muy cerca de los bofedales donde los pisos se mantienen húmedos; ambientes que favorecen la viabilidad de los ooquistes del $T$. gondii en las praderas, incrementando el riesgo de infección.

Con respecto a la edad, las llamas muestran una distribución ascendente y lógica, toda vez que a mayor edad existe una mayor probabilidad de infectarse ( $<<0.05$, Cuadro 2). Por otro lado, las variables edad y zona de muestreo representan un factor de riesgo ( $<<0.0001$, Cuadro 3). Esto coincide con los resultados de Gómez et al. (2003) quien en llamas hembras observó que la edad representa un factor de riesgo.

\section{Conclusiones}

? La seroprevalencia de $T$. gondii en llamas hembras de dos fundos ganaderos de la provincia de Melgar, Puno, fue alta $(47.5 \pm 5.8 \%)$ debido probablemente a la presencia de felinos domésticos y/o silvestres en los lugares de pastoreo.

? La seroprevalencia de $T$. gondii en el fundo San Luis del IVITA-UNMSM fue más alta $(59.6 \pm 6.8 \%)$ que en el Centro 
Experimental de Machuwasi, UNA (19.8 $\pm 6.4 \%$ ), posiblemente debido a la cercanía del primer fundo con centros poblados.

? Los animales de mayor edad tienen un mayor tiempo de exposición a los campos contaminados y por lo tanto, una mayor probabilidad de infectarse con ooquistes.

\section{LITERATURA CITADA}

1. Acha, P.; B. Szyfres. 1992. Zoonosis y enfermedades transmisibles al hombre y los animales. $2^{n}$ ed. p 646-657. OPS. Washington, USA.

2. Calle, R. 1982. Producción y mejoramiento de la alpaca. p 228-229. Ed. Abril-Fondo del Libro. Banco Agrario. Lima.

3. Daniel, W. 1996. Bioestadística base para el análisis de las ciencias de la salud. $5^{2}$ ed. p 205-208. Ed. Limusa. México.

4. Dubey, J.P.; L. Richard; G. Zimmerman; D.M. Mulrooney. 1992. Seroprevalence of Toxoplasma gondii in llamas (Lama glama) in the northwest USA. Vet. Parasitol. 44: 295-298.

5. Elamin, E.A.; S. Elias; A. Daugschies; M. Rommel. 1992. Prevalence of Toxoplasma gondii antibodies in pastoral camels (Camelus dromedarius) in the Butana plains, mid-Estern Sudan. Vet. Parasitol. 43: 171-175.
6. Gómez O.; A. Chávez; E. Casas; E. Serrano; O. Cárdenas. 2003. Determinación de la seroprevalencia de la toxoplasmosis en alpacas y llamas en la estación experimental INIA-Puno. Rev. Inv. Vet. Perú 14: 49-53.

7. Jacobs, L. 1964. Toxoplasmosis. Br. Vet. J. 120: 347-364.

8. Leguía, G.; H. Samamé; C. Guerrero; M. Rojas; A. Nuñez. 1988. Prevalencia de anticuerpos contra Toxoplasma gondii en alpacas. Rev. Camel. Sudam. UNMSM-IVITA-CICCS 6: 19-21.

9. Trees, A.; F. Guy; B. Tennant; A. Balfour; J.P. Dubey. 1993. Prevalence of antibodies to Neospora caninum in a population of urban dogs in England. Vet. Rec. 132:125-126.

10. Rojas, M. 1990. Parasitismo de los rumiantes domésticos. Terapia y prevención y modelos para su aprendizaje. $p$ 326-332. Ed. Maijosa. Lima.

11. Raggi, L. 1992. Camélido. Una opción ganadera. El campesino 123: 16-23.

11. Vidal, L. 1990. Prevalencia de anticuerpos contra Toxoplasma gondii en cabras de la provincia de Lima. Tesis de Médico Veterinario. Facultad de Medicina Veterinaria, Univ. Nacional Mayor de San Marcos. Lima. 46 p.

12. Zhang, S.; M. Wei; Z. Zhou; J. Yu; X. Shi. 2000. Prevalence of antibodies to Toxoplasma gondii in the sera of rare wildlife in the Shangai Zoological Garden, People's Republic of China. Parasit. Internat. 49: 171-174. 